\title{
Living arrangements and life satisfaction: mediation by social support and meaning in life
}

Lin Yan ${ }^{1}$, Xiao Huimin ${ }^{1 *}$, Lan Xiuyan ${ }^{2,3}$, Wen Shuangshuang ${ }^{4}$ and Bao Shaoshao ${ }^{1}$

\begin{abstract}
Background: Living arrangements have impact on life satisfaction among older adults. However, the mechanism how it works has received less attention. This study aims to examine the mediating role of meaning in life and social support in the relationship between living arrangements and life satisfaction.

Methods: A total of 215 older adults from nine nursing homes and three communities were included in this study. The Social Support Rating Scale, Meaning in Life Questionnaire and Life Satisfaction Index A were adopted. Data were analyzed with Hayes's bias-corrected bootstrapping method.

Results: Both social support and presence of meaning in life had positive correlations with life satisfaction ( $p<$ 0.001), and they were significant mediators between living arrangements and life satisfaction $(p<0.01)$.

Conclusion: To improve the life satisfaction of nursing home residents, more emphasis should be placed on encouraging residents to seek or maintain a meaningful life and creating a more positive climate of social support.
\end{abstract}

Keywords: Living arrangements, Life satisfaction, Social support, Meaning in life, Mediation effect

\section{Background}

The global population is aging rapidly. The number of older adults aged 60 years or more is projected to reach two billion by 2050 , or $22 \%$ of the world population [1]. China has the largest elderly population in the world. In Fuzhou of China, the number of people aged 60 years or above is estimated at 1.51 million, comprising $17 \%$ of the total population [2]. Older adults often experience reductions in physical function, cognition, personal autonomy and engagement in social activities $[3,4]$. In many cases, the decision by older adults to relocate to a nursing home, made in consultation with their family, is inevitable. Compared to previous generations, modern Chinese nuclear families are less able to care for aging

\footnotetext{
*Correspondence: huimin_xiao@126.com

'School of Nursing, Fujian Medical University, No. 1 Xuefu North Road, University Town, Fuzhou 3500108, Fujian, China

Full list of author information is available at the end of the article
}

parents. Older adults in China, therefore, are increasingly moving to nursing homes, despite the fact that the vast majority would prefer to remain in their own home [5]. Regardless of where older adults live, life satisfaction is regarded as a key indicator of successful aging [6]. There is a growing interest in exploring how living arrangements affect older adults' life satisfaction, which may contribute to developing and applying strategies for successful aging.

Life satisfaction is defined as an individual's evaluation of his or her attitudes and feelings about life, based on a standard that he or she has set [7]. Convoy model of social relations [8] and Novena's conceptual model of meaning in life [9] further reveal the relationships of life satisfaction, living arrangements, social support and meaning in life. The convoy model indicates that social support from different social networks (e.g. living arrangements) plays an important role in determining 
individual subjective well-being [8], such as life satisfaction. According to the latter model, the conditions (e.g. living arrangements) can serve as a foundation for the components of meaning in life. Feeling happy, satisfied and joyful should be the outcomes of having meaning in life [9]. Theoretically, social support and meaning in life could be the mediators of living arrangements of life satisfaction.

Numerous studies have identified the predictors of life satisfaction among older adults [10-12]. Living arrangements seem to be a fundamental factor related to life satisfaction [13]. A previous study has indicated that community-dwelling older adults showed higher levels of life satisfaction than nursing home residents [14]. This is further confirmed by another study that showed the majority of older adults living in nursing homes had low levels of life satisfaction [15]. Social support could be a significant factor for life satisfaction in older adults too. There is evidence that social support is consistently found to be positively correlated with life satisfaction in older adults [16, 17]. It has emerged as a crucial protective factor for life satisfaction among them [18, 19]. Meaning in life has been also revealed as another significant factor. As motivation and goals can predict positive expectancies, meaning in life may predict enhanced life satisfaction. It has been demonstrated that the presence of a higher level of meaning in life contributes to increasing levels of life satisfaction [20]. Another study also has found that when a sense of meaning in life decreases, satisfaction with life tends to be lower [21].

In addition, social support and meaning in life are also associated with a person's living arrangements. Numerous studies have illustrated significant differences in the social support that is available to people depending on their living arrangements. For example, Su et al. [22] report that empty nesters living in rural areas have access to higher levels of social support than those living in urban areas. Muramatsu, Yin and Hedeker [23] have also revealed that social support is more available to older adults living in a state that is supportive of home- and community-based services. Furthermore, nursing home residents may enjoy less social support, compared to those living with their families. This is mainly due to the fact that moving to a nursing home may lead to the loss of intimate attachments [24]. Among older adults, living arrangements also play an important role in meaning in life. Previous studies have found that older adults who are institutionalized have a lower sense of meaning in life than community-dwelling older adults $[25,26]$.

Although many studies have found a significant relationship among living arrangements, social support, meaning in life and life satisfaction in older adults, to date, no study has examined the effect of social support and meaning in life on the relationship between living arrangements and life satisfaction in older adults. Based on the above mentioned theoretical and empirical background, this study proposes a conceptual model (Fig. 1) to link these variables with life satisfaction. It is hypothesized that living arrangements exerted a direct effect on life satisfaction and an indirect effect mediated by social support and meaning in life. This study aims to provide a new insight into the mediating role of meaning in life and social support between living arrangements and life satisfaction among older adults.

\section{Methods}

\section{Study design and participants}

This was a cross-sectional survey. A total of 215 older adults were conveniently recruited between May 2016 and April 2017. The inclusive criteria were: (a) nursing home residents who had been living in a nursing home for more than 6 months or community-dwelling older adults who were permanent local residents; (b) aged 60 years or older; (c) ability to communicate. The exclusion criteria were as follows: (a) older adults with cognitive impairment, as measured by the Short Portable Mental Status Questionnaire (cut off $\geq 2$ ) [27], and (b) critically ill or in the terminal stage of illness.

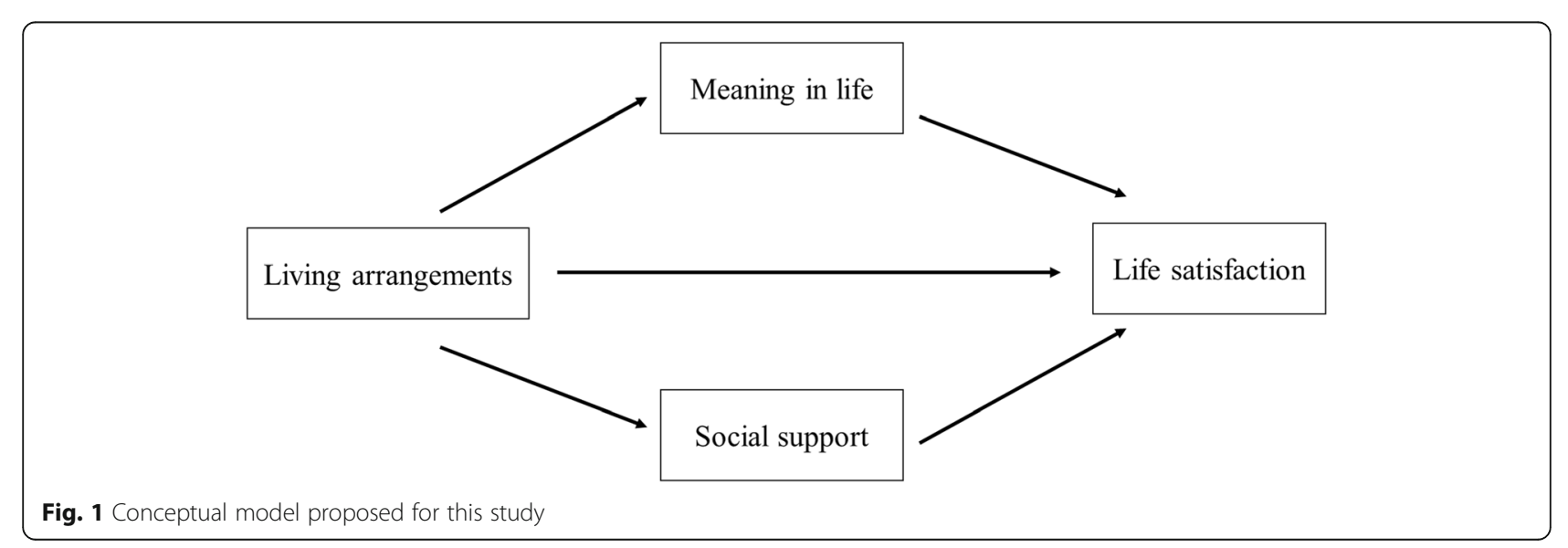




\section{Variables and measures}

\section{Demographic variables}

The sociodemographic variables included age, gender, education level, marital status, income source, occupation, activities of daily living, chronic disease and religion.

\section{Independent variable}

Living arrangement (community vs. nursing home) was the independent variable in this study. The communitydwelling older adults in this study usually lived in their own home and received necessary medical care at a community health center [28]. The nursing home residents received institutional care, including personal care, recreational activities and medical care.

\section{Mediating variables}

Meaning in life and social support were two mediating variables in this study. Meaning in life was measured by Meaning in Life Questionnaire (MLQ), consisting of two five-item subscales, Presence (MLQ-P; perceived meaning) and Search (MLQ-S; motivation to discover meaning) [29]. The Presence subscale measures an individual's perception of the degree to which his or her life is meaningful, such as "I understand my life's meaning". The Search subscale measures an individual's motivation to find meaning in life, such as "I am searching for meaning in my life." All items are rated on a seven-point scale ranging from 1 (absolutely untrue) to 7 (absolutely true). Scores of each subscale range from 5 to 35 . The higher scores indicate higher levels of presence of meaning or search for meaning. The Chinese translation of MLQ was used in this study. Its reliability was confirmed with alpha coefficient estimates of internal consistency of 0.81 and 0.84 , respectively [30]. Social support was assessed using the Social Support Rating Scale [31], which has widely been used among different populations in China [32, 33]. Social support was examined from three dimensions with 10 items: objective support, subjective support, and utilization of support. The scores for the scale range from 12 to 66 . A higher score predicts more social support. The Cronbach's $\alpha$ for the scale was 0.83 [34].

\section{Dependent variable}

In this study, life satisfaction was measured using the Life Satisfaction Index A [35]. The index consists of 20 "agree" or "disagree" attitude items. It assigns one point for positive answers, and no points for negative answers or "don't know" answers. Each item scores 0 to 1 and provides a range of 0 to 20 in total. Higher total scores indicate higher levels of satisfaction. The Cronbach's $\alpha$ for the Chinese version scale was 0.74 [36, 37].

\section{Data collection}

The ethic approval of this study was obtained from the co-responding author's university. Then, our study proposal was sent to the available community committees and nursing homes in Fuzhou to invite them to participate in this study. Nine nursing homes and three communities agreed to be recruited for this study. After the informed consent was obtained, the individual face-toface interviews were conducted by senior undergraduate nursing students with experience in conducting surveys. The data collectors read each question aloud and objectively marked the participants' answers in the questionnaire. Each interview last about $20 \mathrm{~min}$.

\section{Data analysis}

Descriptive statistics were calculated for all of the targeted variables. Categorical variables were described by frequencies and percentage, and continuous variables, by mean and standard deviation. A chi-square test was used to examine the differences in demographic characteristics between community-dwelling older adults and nursing home residents. An independent-sample t-test was used to compare life satisfaction, presence of meaning, search for meaning and social support between the two groups. Additionally, correlational analyses were calculated for life satisfaction, presence of meaning, search for meaning, and social support.

Hayes's bias-corrected bootstrapping method [38] was employed to examine the multiple mediation effects of presence of meaning, search for meaning, and social support. The reason is that although a causal steps approach and the Sobel test enjoy some application in test mediation effects, they have a major flaw $[39,40]$. They require the assumption that the sampling distribution of the indirect effect is normal. But the sampling distribution of indirect effect tends to be asymmetric, with nonzero skewness and kurtosis [41]. Indeed, bootstrapping has more power and better Type I error control than the Sobel test and the causal steps approach [38]. We used 5000 bootstrap samples, and bias was corrected at $95 \%$ confidence intervals $(\mathrm{CI})$ to calculate the indirect effect of each variable. If the $\mathrm{CI}$ of the indirect effect did not include zero, it indicated that the indirect effect was significant.

\section{Results}

\section{Demographic characteristics of study participants}

Table 1 presented the sample characteristics by comparing the frequencies or means between the two settings. There were 101 respondents from long-term nursing homes, and 114 from communities. The mean age of all participants was $75.81(\mathrm{SD}=9.42)$. The proportion of nursing home residents aged 75 or above was significantly larger than that of community residents $(p<0.001)$. Nearly 
Table 1 Participant demographic characteristics

\begin{tabular}{|c|c|c|c|c|c|}
\hline Variable & $\begin{array}{l}\text { Total }(n=215) \\
\mathrm{n}(\%)\end{array}$ & $\begin{array}{l}\text { Nursing Home }(n=101) \\
\mathrm{n}(\%)\end{array}$ & $\begin{array}{l}\text { Community }(n=114) \\
\mathrm{n}(\%)\end{array}$ & $x^{2}$ & $p$ \\
\hline Age (years) & & & & $-7.076^{* * *}$ & 0.000 \\
\hline $60-74$ & $102(47.4)$ & $22(21.8)$ & $80(70.2)$ & & \\
\hline$\geq 75$ & $113(52.6)$ & $79(78.2)$ & $34(29.8)$ & & \\
\hline Marital status & & & & $-6.032^{* * *}$ & 0.000 \\
\hline Married & $98(45.6)$ & $24(23.8)$ & $74(64.9)$ & & \\
\hline Other marital status & $117(54.4)$ & $77(76.2)$ & $40(35.1)$ & & \\
\hline Source of income & & & & $-2.972^{* *}$ & 0.003 \\
\hline Pension & $153(71.2)$ & $62(61.4)$ & $91(79.8)$ & & \\
\hline Other & $62(28.8)$ & 39 (38.6) & $23(20.2)$ & & \\
\hline Gender & & & & -0.353 & 0.724 \\
\hline Male & $90(41.9)$ & $41(40.6)$ & $49(43)$ & & \\
\hline Female & $125(58.1)$ & $60(59.4)$ & $65(57)$ & & \\
\hline Occupation & & & & -0.954 & 0.340 \\
\hline Civil servant & $39(18.1)$ & 19 (18.8) & $20(17.5)$ & & \\
\hline Employee & $91(42.3)$ & 37 (36.6) & $54(47.4)$ & & \\
\hline Other & 85 (39.5) & $45(44.6)$ & $40(35.1)$ & & \\
\hline Education level & & & & -0.678 & 0.498 \\
\hline Primary school & $105(48.8)$ & $52(51.5)$ & $53(46.5)$ & & \\
\hline Middle school & $54(25.1)$ & $24(23.8)$ & $30(26.3)$ & & \\
\hline High school or above & $56(26.1)$ & $25(24.8)$ & $31(27.2)$ & & \\
\hline Chronic disease & & & & -1.526 & 0.127 \\
\hline No & $84(39.1)$ & $34(33.7)$ & $50(43.9)$ & & \\
\hline Yes & $131(61.9)$ & $67(66.3)$ & $64(56.1)$ & & \\
\hline Religion & & & & -0.746 & 0.456 \\
\hline No & $108(50.2)$ & $48(47.5)$ & $60(52.6)$ & & \\
\hline Yes & $107(49.8)$ & $53(52.5)$ & $54(47.4)$ & & \\
\hline
\end{tabular}

half of the respondents were married (45.6\%), however, the proportion of married elderly living in the community (64.9\%) was significantly larger than that of those living in nursing homes $(23.8 \%)$. A total of $71.2 \%$ of respondents were living on a pension, while the rest were living on savings, public assistance or financial support from their children. There was a slightly lower proportion of nursing home residents living on a pension, compared with their counterparts $(61.4 \%$ vs $79.8 \%)$. A $\chi^{2}$ test indicated that no significant differences between the two groups were found in terms of gender, occupation, education level, religion or chronic disease.

\section{Descriptive statistics and correlations among the main variables}

Table 2 showed that social support, presence of meaning, search for meaning, and life satisfaction was different between nursing home residents and community-dwelling

Table 2 Descriptive statistics and correlations among variables $(n=215)$

\begin{tabular}{|c|c|c|c|c|c|c|c|c|c|}
\hline \multirow[t]{2}{*}{ Variable } & \multicolumn{2}{|c|}{ Nursing home $(n=101)$} & \multicolumn{2}{|c|}{ Community $(n=114)$} & \multirow[t]{2}{*}{$\mathrm{t}$} & \multicolumn{4}{|c|}{ Correlations among variables } \\
\hline & $\bar{M}$ & SD & $\bar{M}$ & SD & & 1 & 2 & 3 & 4 \\
\hline (1) Social support & 28.04 & 6.84 & 35.17 & 7.58 & $-7.21^{* * *}$ & 1.000 & $.261^{* *}$ & $.160^{*}$ & $.359^{* *}$ \\
\hline (2) Presence of meaning & 17.41 & 7.79 & 21.79 & 8.76 & $-3.85^{* * *}$ & - & 1.000 & $.745^{* *}$ & $.450^{* *}$ \\
\hline (3) Search for meaning & 15.98 & 8.76 & 19.10 & 6.53 & $-3.60^{* * *}$ & - & - & 1.000 & $.397^{* *}$ \\
\hline (4) Life satisfaction & 11.19 & 3.97 & 13.65 & 3.77 & $-4.66^{* * *}$ & - & - & - & 1.000 \\
\hline
\end{tabular}

$M$ mean, $S D$ standard deviation; ${ }^{* *} p<0.01$ (two-tailed); ${ }^{* * *} p<0.001$ (two-tailed) 
older adults $(p<0.001)$. The nursing home residents reported lower levels of social support, presence of meaning, search for meaning and life satisfaction, compared with the community-dwelling older adults $(p<0.001)$. All three variables were significantly correlated with one another. Social support was positively related to presence of meaning $(\mathrm{r}=$ $0.261, p<0.001)$, search for meaning $(\mathrm{r}=0.160, p<0.05)$ and life satisfaction $(r=0.359, p<0.001)$. Higher level of presence of meaning and search for meaning were all significantly associated with a higher level of life satisfaction $(\mathrm{r}=0.450, p<$ $0.001 ; \mathrm{r}=0.397, p<0.001$ ).

\section{Mediating effects of social support, presence of meaning, and search for meaning}

The findings about the mediation effects of presence of meaning, search for meaning, and social support on the relationship between living arrangements (nursing home vs. community) and life satisfaction were presented in Table 3, and the final path model was presented in Fig. 2. The total effect of living arrangements on life satisfaction was significant $(\mathrm{b}=2.460, \mathrm{SE}=0.528, p<0.001$, bias-corrected and percentile $95 \% \mathrm{CI}=[1.419,3.501])$. The direct effect of living arrangements on life satisfaction was statistically nonsignificant $(p>0.05$, bias-corrected and percentile 95\% CI = $[-0.210,1.899])$. Both presence of meaning and social support were significant in mediating the relationship between living arrangements and life satisfaction $(b=0.531, S E=$ $0.219, p<0.05$, bias-corrected $95 \% \mathrm{CI}=[0.182,1.054]$, percentile $95 \% \mathrm{CI}=[0.163,1.010] ; \mathrm{b}=0.794, \mathrm{SE}=0.274$, $p<0.01$, bias-corrected 95\% CI $=[0.306,1.398]$, percentile $95 \% \mathrm{CI}=[0.311,1.290]$, respectively). Recording to the result of percentile, that showed the statistical analysis of interval contained 0 , search for meaning was not significant in mediating the relationship between living arrangements and life satisfaction $(\mathrm{b}=0.281, \mathrm{SE}=$ $0.166, p<0.05$, bias-corrected $95 \% \mathrm{CI}=[0.027,0.694]$, percentile $95 \% \mathrm{CI}=[-0.008,0.647])$.

\section{Discussion}

This was a descriptive study to explore how living arrangements affect life satisfaction in older adults. It confirmed that community-dwelling older adults had a higher level of life satisfaction than nursing home residents. Importantly, it further revealed that the effect of living arrangements on life satisfaction is totally mediated by presence of meaning in life and social support.

The t-test in this study showed that communitydwelling older adults reported higher levels of life satisfaction, higher levels of social support and greater meaning in life than those living in a nursing home. The more comprehensive life satisfaction path model further indicated that their living arrangements did not directly influence life satisfaction, but had a totally indirect influence through different social and spiritual status. This finding suggested that living in a nursing home did not cause poor life satisfaction, but that mediating factors (social support and presence of meaning in life) exerted an important impact on life satisfaction. The possible reason for community-dwelling older adults with a higher life satisfaction may be also due to place attachments. Scannell and Gifford have revealed that places can emerge various individual and cultural meaning from personally important experiences [42]. This point is consistent with aging in place, which indicates the importance of creating sustainable environments [43].

\section{The mediating effects of presence of meaning}

The present study indicated that the relationship between living arrangements and life satisfaction was mediated by presence of meaning in life. Specifically, the community-dwelling older adults reported higher levels of meaning in life, which was associated with better life satisfaction, compared with nursing home residents. This is supported by Glaw et al., who identified a positive association between meaning in life and life satisfaction [20]. Presence of meaning in life refers to the extent

Table 3 Mediation effects of social support and life meaning on relationship between living arrangements and life satisfaction ( $\mathrm{n}=215$ )

\begin{tabular}{|c|c|c|c|c|c|c|c|}
\hline & \multirow{3}{*}{ Point Estimate } & & & \multicolumn{4}{|c|}{ Bootstrapping } \\
\hline & & \multicolumn{2}{|c|}{ Product of coefficients } & \multicolumn{2}{|c|}{ Bias Corrected 95\% Cl } & \multicolumn{2}{|c|}{ Percentile 95\% C } \\
\hline & & SE & Z & Lower & Upper & Lower & Upper \\
\hline \multicolumn{8}{|l|}{ Total effects } \\
\hline Living arrangement $\rightarrow$ Life satisfaction & 2.460 & 0.528 & $4.659^{* * *}$ & 1.419 & 3.501 & 1.419 & 3.501 \\
\hline \multicolumn{8}{|l|}{ Direct effects } \\
\hline Living arrangement $\rightarrow$ Life satisfaction & 0.845 & 0.535 & 1.579 & -0.210 & 1.899 & -0.210 & 1.899 \\
\hline \multicolumn{8}{|l|}{ Indirect effects } \\
\hline Total Indirect Effects & 1.615 & 0.364 & $4.437^{* * *}$ & 0.994 & 2.448 & 0.945 & 2.386 \\
\hline Living arrangement $\rightarrow$ Presence of meaning $\rightarrow$ Life satisfaction & 0.531 & 0.219 & $2.309^{*}$ & 0.182 & 1.054 & 0.163 & 1.010 \\
\hline Living arrangement $\rightarrow$ Search for meaning $\rightarrow$ Life satisfaction & 0.281 & 0.166 & 1.624 & 0.027 & 0.694 & -0.008 & 0.647 \\
\hline Living arrangement $\rightarrow$ Social support $\rightarrow$ Life satisfaction & 0.794 & 0.274 & $2.819^{* *}$ & 0.306 & 1.398 & 0.311 & 1.290 \\
\hline
\end{tabular}




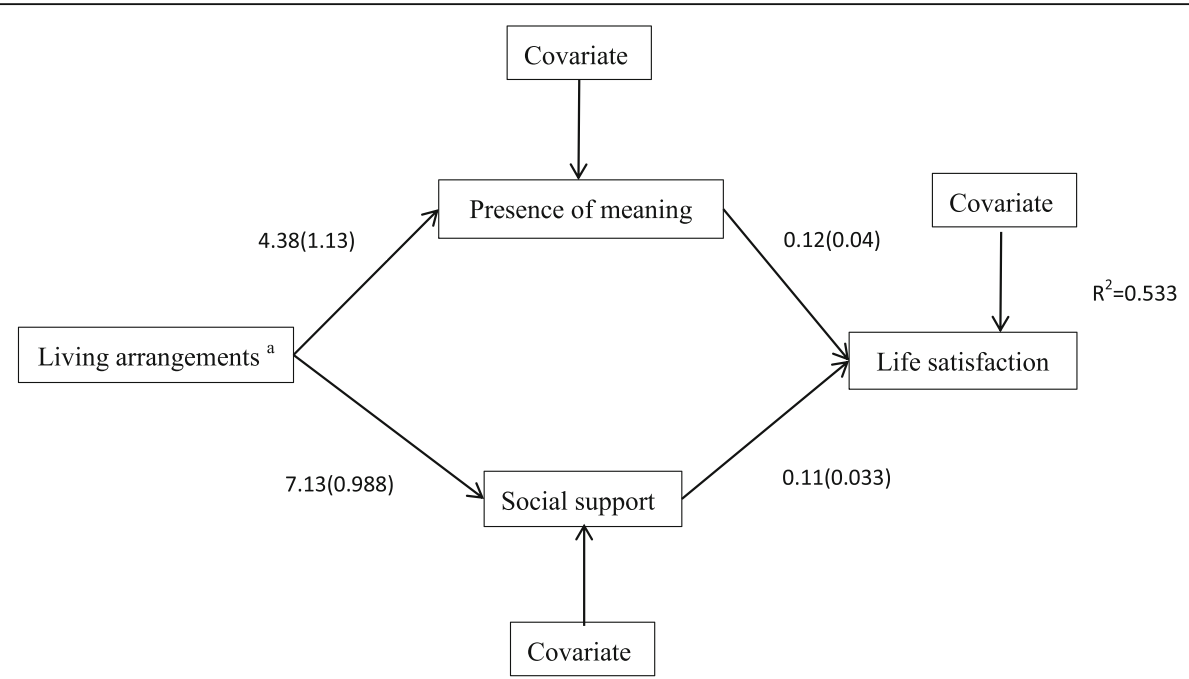

Fig. 2 Results of final path model $(\mathrm{N}=215)$. Note. Higher scores of life satisfaction, social support and presence of meaning scores indicate better status; Covariates for presence of meaning (age, martial status, source of income, gender,occupation, education, chronic disease status, and religion), social support (age, martial status, source of income, gender,occupation, education, chronic disease status, and religion), and life satisfaction (age, martial status, source of income, gender,occupation, education, chronic disease status, and religion) were included in the path model. a. The reference group was a nursing home setting

to which people comprehend, make sense of, or perceive significance in their lives, as well as the degree to which they view themselves as having a purpose or mission [29]. It may be that presence of meaning in life was related to higher levels of well-being and mental health throughout the human life span [44]. It may also be possible that presence of meaning in life can protect individuals from negative outcomes [45], and make them less vulnerable to psychopathology [46]. Another explanation could be that individuals with higher levels of meaning in life can cope more effectively with physical health challenges and overcome obstacles more easily [47].

\section{The mediating effects of social support}

This study further revealed that a positive relationship between living arrangements and life satisfaction was mediated by social support. It suggested that compared to nursing home residents, community-dwelling older adults enjoy higher levels of social support, which was associated with better life satisfaction. Cumulative evidence showed that social support contributed to improved psychological well-being [48]. In this study, it may be that community-dwelling older adults receive more support than older adults living in nursing homes, particularly physical, psychological, emotional, and financial support from their family and children [49-51]. Being deeply engaged with family members contributes to higher levels of life satisfaction. It may also be possible that social support can alleviate the negative effects of stressful events, contributing to greater life satisfaction [52]. Older adults face negative events, such as a reduction in physical functioning and cognition, an increase in dependency and the death of loved ones. Social support was found to be a protector from the negative effects of age-related challenges in older adults $[53,54]$. Thus, older adults who are more engaged in social support networks are more likely to be satisfied with their lives.

These study findings are particularly important, which open a new nursing perspective, because the mediating effects on the relationship between living arrangements and life satisfaction provide evidence for improving nursing home residents' life satisfaction. Given the importance of meaning in life, logotherapy could be a likely contributor to stimulating nursing home residents' will to find meaning in life through three different ways including "creative values," "experiential values," and "attitudinal values" $[55,56]$. Nursing staff could also guide older adults to set small goals, and help them fulfill these goals in their daily lives. They could facilitate residents to offer reminiscence activities and contributions, and help them clarify their values and what brings them meaning in life. Maximizing the social integration of the residents are also necessary. Nursing home staff could hold a variety of activities to increase residents' opportunities to interact with one another and encourage them to engage in more social activities. In particular, for those who are less mobile, nursing home staff could offer opportunities for interaction by escorting them to other residents' rooms, and maximize the opportunities for meeting other residents during activities, not by solely sitting them next to each other. Ensuring good relationships between nursing home staff and residents would be another effective approach to improve social 
support for nursing home residents. Maintaining close ties with family and friends, are also good options for enhancing their life satisfaction. Following this, researchers might explore how older adults place attachment-related resilience and/or belonging in relation to life satisfaction.

\section{Limitations}

The results and implications of this study should be considered in light of several limitations. First, the data were collected at one point in time, and this study did not examine the modeled relationships longitudinally or test the models' predictive power over time. Second, this study only 215 older adults from nine nursing homes and three communities in southeastern China. The findings' generalizability is limited. Finally, the sole use of self-reported measures and a convenience sampling procedure are also methodological limitations, it could have been strengthened to use a mixed methods involving interviews with participants would provide more context to complement the quantitative findings.

\section{Conclusion}

The study provides additional evidence of the importance of presence of meaning in life and social support for life satisfaction in older adults from different living arrangements. To improve the life satisfaction of nursing home residents, more emphasis should be placed on encouraging residents to seek or maintain a meaningful life and on creating a more positive climate of social support.

\section{Abbreviations}

MLQ: Meaning in life questionnaire; MLQ-P: Meaning in life questionnairepresence; MLQ-S: Meaning in life questionnaire-search; Cl: Confidence interval; M: Mean; SD: Standard deviation; SE: Standard Error

\section{Acknowledgements}

The authors sincerely thank the older adults from the communities and nursing homes.

\section{Authors' contributions \\ $Y L$ supervised the data collection, conducted the statistical analysis, and wrote the paper. HM X was responsible for designing the study and the study's statistical design, supervising the data collection, as well as assisting with writing the article. $X Y L$ collected the data and assisted with writing the article. SS W collected the data and assisted with the statistical analysis. SS B collected the data. All authors critically reviewed the paper. The author(s) read and approved the final manuscript.}

\section{Funding}

This study was supported by a grant from Fujian Medical University Professor Funding (JS14014). The funder has no role in study design, data collection and analysis, or preparation of manuscript.

\section{Availability of data and materials}

The data that support the findings of this study are available from the corresponding author on request.

\section{Ethics approval and consent to participate}

Ethical approval for the study was obtained from the Human Ethics Committee of Fujian Medical University (ethics approval number: 2015-56). Informed written consent was obtained from all individual participants included in the study.
Consent for publication

Not applicable.

\section{Competing interests}

The authors have no conflict of interests to disclose.

\section{Author details}

${ }^{1}$ School of Nursing, Fujian Medical University, No. 1 Xuefu North Road, University Town, Fuzhou 3500108, Fujian, China. ${ }^{2}$ Fujian Provincial Hospital, Fuzhou, China. ${ }^{3}$ Fujian Medical University Affiliated Clinical Medical Institute, Fuzhou, China. ${ }^{4}$ The Eighth Affiliated Hospital, Sun Yat-sen University, Shenzhen, China.

Received: 25 August 2019 Accepted: 29 March 2020

Published online: 15 April 2020

\section{References}

1. World Health Organization. facts about aging. 2014 http://www.who.int/ ageing/about/facts/zh/. Accessed 20 Aug 2018.

2. Fzuzhou Govermenment issued ageing development in the $13^{\text {th }}$ five-year plan period. http://www.fuzhou.gov.cn/zfxxgkzl/szfbmjxsqxxgk/szfbmxxgk/ fzsrmzf/zfxxgkml/gmjjhshfzghzxghqyghjxgzc/201801/t20180123_2002493. htm. Accessed 23 Jan 2018.

3. Kim SY, Sok SR. Relationships among the perceived health status, family support and life satisfaction of older Korean adults. Int J Nurs Pract. 2012; 18(4):325-31.

4. Lyyra TM, Törmäkangas TM, Read S, et al. Satisfaction with present life predicts survival in octogenarians. J Gerontol B Psychol Sci Soc Sci. 2006; 61(6):319-26.

5. Jin C, Zheng Z, Xian W, et al. Gender differences in positive life orientation among the nursing home elders in China: a cross-sectional study. Arch Gerontol Geri. 2017;72:86-90

6. Meléndez J, Tomás J, Oliver A, Navarro E. Psychological and physical dimensions explaining life satisfaction among the elderly: a structural model examination. Arch Gerontol Geriatr. 2009;48(3):291-5.

7. Diener E. Subjective well-being. Psychol Bull. 1984;95(3):542-75.

8. Antonucci TC, Birditt KS, Akiyama H. Convoys of social relations: An interdisciplinary approach. In: Bengston VL, Gans D, Pulney NM, Silverstein $M$, editors. Handbook of theories of aging. New York: Springer Publishing Co; 2009. p. 247-60.

9. Noviana U, Miyazaki M, Ishimaru M. Meaning in life: a conceptual model for disaster nursing practice. Int J Nurs Pract. 2016;22(S1):65-75. https:// onlinelibrary.wiley.com/doi/abs/10.1111/ijn.12441.

10. Kooshiar H, Yahaya N, Hamid TA, et al. Living arrangement and life satisfaction in older Malaysians: the mediating role of social support function. PLoS One. 2012;7(8):e43125.

11. Yan B, Gao X, Lyon M. Modeling satisfaction amongst the elderly in different Chinese urban neighborhoods. Soc Sci Med. 2014;118:127-34.

12. Fernández-Portero C, Alarcón D, Barrios PÁ. Dwelling conditions and life satisfaction of older people through residential satisfaction. J Environ Psychol. 2017;49:1-7.

13. Kostka $T$, Jachimowicz $V$. Relationship of quality of life to dispositional optimism, health locus of control and self-efficacy in older subjects living in different environments. Qual Life Res. 2010;19:351-61.

14. Gueldner SH, Loeb S, Morris D, et al. A comparison of life satisfaction and mood in nursing home residents and community-dwelling elders. Arch PsychiatrNurs. 2001;15:232-40.

15. Pardal A, Espirito-Santo $H$, Lemos L, et al. Social suport, mental health, and satisfaction with life in institutionalized elderly. Eur Psychiatry. 2013;28:1-1.

16. Dumitrache CG, Rubio L, Rubio-Herrera R. Perceived health status and life satisfaction in old age, and the moderating role of social support. Aging Ment Health. 2018;22:1063-71.

17. Park J, Roh S, Yeo Y. Religiosity, social support, and life satisfaction among elderly Korean immigrants. Gerontologist. 2012;52:641-9.

18. Felmlee D, Muraco A. Gender and friendship norms among older adults. Res Aging. 2009;31:318-44.

19. Kang SM, Shaver PR, Sue S, et al. Culture-specific patterns in the prediction of life satisfaction: roles of emotion, relationship quality, and self-esteem. Personal Soc Psychol Bull. 2003;29:1596-608. 
20. Glaw X, Kable A, Hazelton M, et al. Meaning in life and meaning of life in mental health care: an integrative literature review. Issues Ment Health Nurs. 2017;38:243-52

21. Ryff CD, Singer BH, Dienberg LG. Positive health: connecting well-being with biology. Philos Trans R Soc Lond Ser B Biol Sci. 2004;359(1449):1383-94.

22. Su D, Wu XN, Zhang YX, et al. Depression and social support between China' rural and urban empty-nest elderly. Arch GerontolGeriatr. 2012;55: 564-9.

23. Muramatsu N, Yin H, Hedeker D. Functional declines, social support, and mental health in the elderly: does living in a state supportive of home and community-based services make a difference? Soc Sci Med. 2010;70:1050-8.

24. Sundström G, Fransson E, Malmberg B, et al. Loneliness among older Europeans. Eur J Ageing. 2009;6:267-75.

25. Haugan $\mathrm{G}$. The relationship between nurse-patient interaction and meaning-in-life in cognitively intact nursing home patients. J Adv Nurs. 2014;70(1):107-20.

26. Ghadampour E, Heidaryani L, Radmehr F. The compare and relationship between the meaning in life and self-esteem and quality of life of elderly living at home and living in nursing home. Avicenna J Nurs Midwifery care. 2018;26(5):315-22.

27. Pfeiffer E. A short portable mental status questionnaire for the assessment of organic brain deficit in elderly patients. J Am Geriatr Soc. 1975;23:433-41.

28. Xiao H, Yoon J, Bowers B. Living arrangements and quality of life: mediation by physical function and depression. West J Nurs Res. 2016;38:738-52.

29. Steger MF, Frazier $P$, Oishi $S$, et al. The meaning in life questionnaire: assessing the presence of and search for meaning in life. J Couns Psychol. 2006;53:80-93.

30. Chen W, Ge Y, Hu YY, et al. Applicability and generalizability of the revised meaning in life questionaire: based on classical test and Mulitudimensional Rasch model. Chin J Clin Psycholo. 2015;23:604-7.

31. Xiao SY. The theoretical basis and application of social support questionnaire. J Clin Psychi. 1994;4:98-100

32. Ma L, Li Y, Wang J, et al. Quality of life is related to social support in elderly osteoporosis patients in a Chinese population. PLoS One. 2016;10(6): e0127849.

33. Ma W, Kang D, Song Y, et al. Social support and HIV/STDs infections among a probability-based sample of rural married migrant women in Shandong Province. China BMC Public Health. 2015;15:1170.

34. Xie $H$, Peng W, Yang $Y$, et al. Social support as a mediator of physical disability and depressive symptoms in Chinese elderly. Arch PsychiatrNurs. 2017:32:256

35. Neugarten BL, Havighurst RJ, Tobin SS. The measurement of life satisfaction. J Gerontol. 1961;16:134.

36. Li M, Li N, Gao R, et al. Social support and mental health of persons with disabilities: the mediating role of life satisfaction. Psychol Res. 2016;9:54-60

37. Wang $Y$, Huang $M$. The structural equation model of life satisfaction and subjective well-being of the elderly in the morning practice Chinese. Gerontol. 2011;31:4657-9.

38. Hayes AF, Beyond Baron, Kenny. Statistical mediation analysis in the new millennium. CommunMonogr.2009;76:408-420.

39. Baron RM, Kenny DA. The moderator-mediator variable distinction in social psychological research: conceptual, strategic, and statistical considerations. J Pers Soc Psychol. 1986;51:1173-82.

40. Sobel ME. Some new results on indirect effects and their standard errors in covariance structure models. Socio Meth. 1986;16:159-86.

41. Stone CA, Sobel ME. The robustness of estimates of total indirect effects in covariance structure models estimated by maximum. Psychometrika. 1990; 55:337-52.

42. Scannell L, Gifford R. Defining place attachment: a tripartite organizing framework. J Environ Psychol. 2010;30(1):1-10.

43. Fang ML, Woolrych R, Sixsmith J, et al. Place-making with older persons: Establishing sense-of-place through participatory community mapping workshop. Soc Sci Med. 2016;168:223-9.

44. Güler B, Lightsey OR, Can A. The Turkish version of the meaning in life questionnaire: assessing the measurement invariance across Turkish and American adult samples. J Pers Assess. 2013;95(5):551.

45. Pearson PR, Sheffield BF. Psychoticism and purpose in life. PersIndivid Dif. 1989:10:1321-2

46. Debats DL. Sources of meaning: an investigation of significant commitments in life. J Humanist Psychol. 1999;39:30-57.
47. King LA, Hicks JA, Krull JL, et al. Positive affect and the experience of meaning in life. J Pers Soc Psychol. 2006;90:179-96.

48. Bøen H, Dalgard OS, Bjertness E. The importance of social support in the associations between psychological distress and somatic health problems and socio-economic factors among older adults living at home: a cross sectional study. BMC Geriatr. 2012;12:1-12.

49. Nikmat A, Al-Mashoor S, Hashim N. Quality of life in people with cognitive impairment: nursing homes versus home care. Int Psychogeriatr. 2015;27: 815-24.

50. Yang-Tzu L, Tao-Hsin T. Effects of protective factors on the depressive status of elderly people in Taiwan. Medicine (Baltimore). 2020;99:e18461.

51. Tsuji K, Khan HTA. Exploring the relationship between social support and life satisfaction among rural elderly in Japan. Ageing Int. 2016;41(4):414-26.

52. Krause N. Lifetime trauma, emotional support, and life satisfaction among older adults. Gerontologist. 2019;44:615-23.

53. Gow AJ, Pattie A, Whiteman MC, et al. Social support and successful aging: investigating the relationships between lifetime cognitive change and life satisfaction. J Indiv Differ. 2007;28:103-15.

54. Hatfield J, Hirsch J, Lyness J. Functional impairment, illness burden, and depressive symptoms in older adults: does type of social relationship matter? Int J Geriatr Psychiatry. 2013;28:190-8.

55. Reker GT. Personal meaning, optimism, and choice: existential predictors of depression in community and institutional elderly. Gerontologist. 1997;37: 709-16.

56. Matti A. Dattilio frank M.. enhancing cognitive behavior therapy with logotherapy: techniques for clinical practice. Psychotherapy (Chic). 2013;50: 387-91.

\section{Publisher's Note}

Springer Nature remains neutral with regard to jurisdictional claims in published maps and institutional affiliations.

Ready to submit your research? Choose BMC and benefit from:

- fast, convenient online submission

- thorough peer review by experienced researchers in your field

- rapid publication on acceptance

- support for research data, including large and complex data types

- gold Open Access which fosters wider collaboration and increased citations

- maximum visibility for your research: over $100 \mathrm{M}$ website views per year

At BMC, research is always in progress.

Learn more biomedcentral.com/submissions 